\title{
Present scenario of insecticide resistance in Rusty Grain Beetle, Cryptolestes ferrugenius (Stephens) to Malathion and Deltamethrin in Andhra Pradesh, India
}

\author{
Debjyoti Chakraborty ${ }^{*}$ and T. Madhumathi
}

\author{
Department of Entomology, Agricultural College, Bapatla - 522 101, Acharya N.G. Ranga \\ Agricultural University, Andhra Pradesh, India \\ *Corresponding author
}

\begin{abstract}
A B S T R A C T
Keywords

Cryptolestes

ferrugenius,

Malathion,

Deltamethrin,

Population,

Insecticide

resistance

Article Info

Accepted:

20 May 2020

Available Online:

10 June 2020

A laboratory experiment was carried out with insecticide resistance levels of malathion and deltamethrin against different populations of rusty grain beetle during 2017-18. Cryptolestes ferrugenius populations showed 34.66 and 16.66 folds resistant at $\mathrm{LC}_{50}$ level to malathion (from Machilipatnam and Bapatla, respectively) in comparison to laboratory susceptible Rajahmundry population. Bapatla populations showed 1.75 folds of resistance to deltamethrin and remaining Machilipatnam population has recorded 21.35 folds of resistance to deltamethrin at $\mathrm{LC}_{50}$ level when compared with the succeptible Rajahmundry population at 72 hours after treatment. Machilipatnam population of C. ferrugineus was 4.14 and 9.89 folds resistant at $\mathrm{LC}_{99.9}$ level to malathion and deltamethrin, respectively in comparison with susceptible Rajahmundry population. Similarly, Bapatla population of $C$. ferrugineus was 1.92 and 2.57 folds resistant at $\mathrm{LC}_{99.9}$ level to malathion and deltamethrin, respectively.
\end{abstract}

\section{Introduction}

Food grains constitute the bulk of diet of the people. In India, with the advent of green revolution, the food grain production has gone up from $50 \mathrm{~m}$ to $292.95 \mathrm{~m} \mathrm{t}$ in $2019-20$ (Agricultural statistics at a glance, 2019-20). In India large quantities of food grains are stored by Food Corporation of India, central and state warehousing corporations and other agencies not only to maintain adequate food supply but also to meet buffer and reserve stocks to face the natural calamities. Insects infest the crops and cause damage both in the field and storage. The percentage loss by storage pests is 10-12.5 i.e., five percent at farm level and six per cent at trade level (Aulakh et al., 2013). If storage pests continuously attack for six months then the loss would be 50 per cent.

The losses due to insect pests are 3.4 percent, rodents 0.3 to 1.0 percent, moisture 0.2 percent and other sources 0.3 percent (Srinivasa et al., 2003). During storage, various biotic and abiotic factors are 
responsible in deterioration of physical and chemical quality of the food grains and amongst the biotic factors, insect pests cause the major damage (Badmin, 1990).

Among the several storage insect pests, rusty grain beetle cryptolestes ferrugineus (stephens) (cucujidae: coleoptera), is an important and destructive insect pests of stored cereals, oilseeds, miscellaneous food grains and is cosmopolitan in distribution. It feeds on the germ portion of the grain in preference to endosperm (Pingale, 1976).

These insect species have been reported in the Philippines, Japan, Indonesia and Indian subcontinent. Hill (1992) too stated that $C$. ferrugineus was cosmopolitan in distribution, found throughout the warmer regions of the world, and also in some parts of temperate regions in the United Kingdom, Europe and North america. Though this pest has been considered as a secondary pest, incidence will be wide in humid areas when temperature and relative humidity are high especially in coastal regions with high population build up. Resistance of insect pests to pesticides is an example of evolution of the species showing how they can survive and change physiologically under pressure by chemicals.

A better understanding of pest resistance and its effective management will go a long way in providing 'food for all' and 'health for all'. Keeping these in view, an experiment carried out with the objective of present scenario of insecticide resistance in rusty grain beetle, $C$. ferrugineus to Malathion and Deltamethrin in Andhra Pradesh.

\section{Materials and Methods}

\section{Collection of the test insect}

The field population of the test insect $C$. ferrugineus were collected from State ware house corporation (SWC), Bapatla; Central ware house corporation (CWC), Machilipatnam; susceptible culture from FCI, Rajahmundry were subjected to bioassay.

\section{Bioassay}

The adult beetles of $C$. ferrugineus of one day old were subjected to the bioassay with the test insecticides by following jute cloth disc impregnation method. One per cent concentration of stock solution of test insecticides was prepared by weighing the required quantity of malathion and deltamethrin and dissolved in acetone.

The graded concentrations of the test insecticides were prepared with acetone as solvent by following serial dilution technique. Two ml of insecticidal solution was found to be sufficient for complete impregnation of the jute cloth disc of nine $\mathrm{cm}$ diameter. After impregnation, the jute cloth discs were air dried. One week old beetles were collected from the culture and were kept under starvation for two hours.

The starved beetles were transferred to the petri plates containing insecticide impregnated jute cloth disc @ 20 beetles/ petri plate in three replications for each test insecticide. The insects were confined to the treated surface for 24 hours and survivals were transferred into a fresh petri plate with diet. Simultaneously, a control was also maintained which containing jute cloth disc impregnated with acetone only.

\section{Data Collection}

Mortality data were recorded at 24, 48 and 72 hours after treatment (HAT). A preliminary experiment was conducted with wide range of concentrations followed by a narrow range to get mortality in the range of $5-90 \%$. There was no occasion of the use of Abbott's 
formula since mortality was not recorded in control, because of the use of almost same age beetles and the experiment conducted under controlled ambient conditions of $32{ }^{\circ} \mathrm{C}$ temperature and 75 percent relative humidity.

Moreover, a separate set of petri plates were utilized for control avoiding the use of petri plates that were used for insecticidal treatments. In order to know the immediate toxicity of the chemical, the mortality data were recorded at $24 \mathrm{HAT}$ and subsequently at 48 HAT. Mortality data at 72 HAT was also recorded to know the mortality end point.

\section{Assessment of the Degree of Resistance}

The mortalities of adult beetles of $C$. ferrugineus collected from State ware house corporation (SWC), Bapatla; Central ware house corporation (CWC), Machilipatnam; FCI, Rajahmundry; (susceptible) populations against all the test insecticides were subjected to probit analysis (Finney, 1971).

\section{Statistical analysis}

Data was analyzed by using Probit analysis in SPSS 16.0 v. (Statistical Package for Social Sciences) software to calculate $\mathrm{LC}_{50}, \mathrm{LC}_{99.9}$, heterogeneity $\left(\chi^{2}\right)$, intercept: (a), slope of the regression line (b), regression equation and fiducial limits. The degree of resistance acquired by $C$. ferrugineus were calculated for the data at 72 HAT.

The resistance factor was calculated by dividing the LC50 / LC99.9 value of each population with the LC50 / LC99.9 value of susceptible population. The log concentration probit (lcp) lines were drawn by plotting log concentrations on $\mathrm{X}$-axis and probits on $\mathrm{Y}$ axis and the response of test insect populations was studied at different concentrations of the test insecticides (Raffa and Priester, 1985).

\section{Results and Discussion}

\section{Toxicity of Malathion to different populations of $C$. ferrugineus}

\section{Bapatla population}

The $\mathrm{LC}_{50}$ and $\mathrm{LC}_{99.9}$ values of malathion for Bapatla population of at 24 HAT were 0.139 and 2.964 per cent respectively (Table 4.6). Since there was a slight increase in the mortality of adults at 48 and $72 \mathrm{HAT}$, there was a decrease in the $\mathrm{LC}_{50}(0.085 \%$ and 0.050 $\%)$ and $\mathrm{LC}_{99.9}$ values $(2.392 \%$ and $2.278 \%)$. The slope (b) of log concentration probit (lcp) lines of malathion were $1.79,1.79$ and 1.87 at 24, 48 and 72 HAT, respectively (Table. 1).

\section{Machilipatnam population}

The Machilipatnam population of $C$. ferrugineus recorded the $\mathrm{LC}_{50}$ and $\mathrm{LC}_{99.9}$ values of 0.225 and 6.35 per cent, respectively to malathion at $24 \mathrm{HAT}$. The corresponding values of $\mathrm{LC}_{50}$ and $\mathrm{LC}_{99.9}$ obtained after 48 HAT $(0.169 \%$ and $5.11 \%)$ and 72 HAT $(0.104 \%$ and $4.90 \%)$ indicated that there has been a marginal increase in the mortality of insects as time lapsed. The slope (b) of log concentration probit (lcp) lines for Machilipatnam population were $1.87,1.78$ and 1.87 at 24, 48 and 72 HAT, respectively. The chi-square test revealed the homogeneity of the test population $(\mathrm{P}<0.05 \%)$ (Table. 1$)$.

\section{Susceptible Rajahmundry population}

The $\mathrm{LC}_{50}$ and $\mathrm{LC}_{99.9}$ values of malathion for susceptible Rajahmundry population of $C$. ferrugineus at 24 HAT were 0.011 and 1.987 per cent respectively. Since there was a slight increase in the mortality of adults at 48 and 72 HAT, there was a decrease in the $\mathrm{LC}_{50}$ $(0.006 \%$ and $0.003 \%)$ and $\mathrm{LC}_{99.9}$ values ( $1.671 \%$ and $1.184 \%$ ) (Table 1) The slope (b) values of $\log$ concentration probit (lcp) lines 
of malathion were 2.22, 1.56 and 1.43 at 24, 48 and 72 HAT, respectively (Table. 1).

Degree of resistance acquired by adults of C. ferrugineus to malathion at 72 HAT

Among the three population of $C$. ferrugineus, Rajahmundry population has recorded lowest $\mathrm{LC}_{50}$ and $\mathrm{LC}_{99.9}$ values. Hence relative degree of resistance was calculated. The Machilipatnam population and Bapatla populations of $C$. ferrugineus were 34.66 and 16.66 folds resistant at $\mathrm{LC}_{50}$ and 4.14 and 1.92 folds resistant at $\mathrm{LC}_{99.9}$ level to malathion, respectively in comparison with Rajahmundry susceptible population $\left(\mathrm{LC}_{50}=0.003 \%\right.$ and $\left.\mathrm{LC}_{99.9}=1.189 \%\right)$ (Table. 3).

In the present study the $\mathrm{LC}_{50}$ and $\mathrm{LC}_{99.9}$ values of malathion for Machilipatnam were 0.104 and $4.90 \%$ which were lower than the values (0.17 and 8.4793) reported by Madhumathi et al., 2000 which revealed decrease in the levels of resistance to malathion which may be decrease in usage of malathion and due to the alternative usage of deltamethrin in the godowns. However when compared to Rajahmundry populations, this Machilipatnam population of $C$. ferrugineus was still found to be tolerant to malathion.

Malathion has been in use as a common insecticide for postharvest insect control in the United States since 1958. Its use spread to several countries in the 1960s, and its intensive use against stored grain insect pests resulted in the development of severe resistance in many insect species (Champ and Dyte 1976). Several studies in the past have also shown that many OP insecticides including malathion resulted in the development of resistance in many insect species including rusty grain beetle (Badmin, 1990; Rossiter et al., 2001). Sublethal doses of malathion greatly suppressed AcP (acid phosphatase) activity in resistant beetles, which might be due to inhibition of this enzyme under insecticidal toxicity and impairing of the lysosomal activity to hydrolyze the macromolecules and in turn limiting the ability of the resistant beetles to use energy rich compounds to obtain energy.

The above results are on similar line with White and Bell (1995) who reported that the adults of six populations of $C$. ferrugineus behaved differently when exposed to malathion under laboratory conditions.

These populations showed different levels of resistance to malathion. Similarly White and Watters (1983) reported that in UK and Canada, out of four laboratory populations and 19 field populations of C. ferrugineus collected in 1982, two populations from Colonsay and Brunkild had only 80 per cent knock down at a discriminating dose of $0.0088 \mathrm{mg}$ a.i./.m $\mathrm{cm}^{2}$ of malathion. This incomplete knock down might be due to malathion resistance.

In the present study, increased levels of resistance to malathion in Machilipatnam and Bapatla populations of $C$. ferrugineus observed. The toxicity of most organophosphate insecticides applied as residual crack and crevice treatments to control insects in and around gowdons, mills and processing plants is positively correlated with the temperature.

Malathion being one of the oldest insecticide that has been registered nearly for more than five decades, its low cost, moderate toxicity to mammals and optimal residual activity in storage godowns are reasons of support for continuous and wide use in the control of the stored product insects and thus resulted in the widespread and increased level of resistance to $C$. ferrugineus. 
Table.1 Relative toxicity of malathion to different populations of rusty grain beetle, Cryptolestes ferrugenius from different regions of Andhra Pradesh

\begin{tabular}{|c|c|c|c|c|c|c|}
\hline $\begin{array}{l}\text { S. } \\
\text { No. }\end{array}$ & HAT & $\begin{array}{c}\mathrm{LC}_{50}(95 \% \mathrm{FL}) \\
(\%)\end{array}$ & $\begin{array}{c}\mathrm{LC}_{99.9}(95 \% \mathrm{FL}) \\
(\%)\end{array}$ & Slope b $( \pm \mathrm{SE})$ & $\begin{array}{l}\text { Heterogeneity } \\
\qquad\left(\chi^{2}\right)\end{array}$ & $\begin{array}{l}\text { Regression equation } \\
\qquad(\mathbf{Y}=\mathbf{a}+\mathbf{b x})\end{array}$ \\
\hline \multicolumn{7}{|c|}{ BAPATLA POPULATION } \\
\hline 1 & 24 & $0.139(0.102-0.227)$ & $2.964(0.961-7.765)$ & $1.79( \pm 0.176)$ & 13.18 & $Y=1.57+1.79 x$ \\
\hline 2 & 48 & $0.085(0.054-0.129)$ & $2.392(0.766-6.764)$ & $1.79( \pm 0.145)$ & 18.99 & $Y=2.07+1.79 x$ \\
\hline 3 & 72 & $0.050(0.027-0.074)$ & $2.278(0.772-3.837)$ & $1.87( \pm 0.129)$ & 23.90 & $Y=2.39+1.87 x$ \\
\hline \multicolumn{7}{|c|}{ MACHILIPATNAM POPULATION } \\
\hline 1 & 24 & $0.225(0.164-.449)$ & $6.35(3.45-24.225)$ & $1.87( \pm 0.201)$ & 16.13 & $Y=1.58+1.87 x$ \\
\hline 2 & 48 & $0.169(0.124-.291)$ & $5.11(2.50-20.121)$ & $1.78( \pm 0.165)$ & 17.92 & $Y=2.57+1.78 x$ \\
\hline 3 & 72 & $0.104(0.062-.197)$ & $4.90(2.09-13.121)$ & $1.87( \pm 0.133)$ & 21.73 & $Y=3.17+1.87 x$ \\
\hline \multicolumn{7}{|c|}{ SUSCEPTIBLE RAJAHMUNDRY POPULATION } \\
\hline 1 & 24 & $0.011(0.008-0.015)$ & $1.987(0.653-6.121)$ & $2.22( \pm 0.119)$ & 4.66 & $Y=1.12+2.22 x$ \\
\hline 2 & 48 & $0.006(0.004-0.010)$ & $1.671(0.451-4.375)$ & $1.56( \pm .109)$ & 2.02 & $Y=1.51+1.56 x$ \\
\hline 3 & 72 & $0.003(0.049-6.470)$ & $1.184(0.049--2.421)$ & $1.43( \pm .106)$ & 5.54 & $Y=1.86+1.43 x$ \\
\hline
\end{tabular}

Lethal concentrations and 95\% fiducial limits (fl) were estimated using probit analysis (spss 16.0).

The chi-square test revealed the homogeneity of the test population $(\mathrm{p}<0.05 \%)$ 
Table.2 Relative toxicity of deltamethrin to different populations of rusty grain beetle, Cryptolestes ferrugenius from different regions of Andhra Pradesh

\begin{tabular}{|c|c|c|c|c|c|c|}
\hline $\begin{array}{l}\text { S. } \\
\text { No. }\end{array}$ & HAT & $\begin{array}{c}\mathrm{LC}_{50}(95 \% \mathrm{FL}) \\
(\%)\end{array}$ & $\begin{array}{c}\mathrm{LC}_{99.9}(95 \% \mathrm{FL}) \\
(\%)\end{array}$ & Slope b $( \pm$ SE $)$ & $\begin{array}{l}\text { Heterogeneity } \\
\qquad\left(\chi^{2}\right)\end{array}$ & $\begin{array}{l}\text { Regression equation } \\
(\mathbf{Y}=\mathbf{a}+\mathbf{b x})\end{array}$ \\
\hline \multicolumn{7}{|c|}{ BAPATLA POPULATION } \\
\hline 1 & 24 & $0.017(0.012-0.030)$ & $3.398(0.371-8.370)$ & $2.29( \pm 0.186)$ & 4.059 & $Y=1.6+2.29 x$ \\
\hline 2 & 48 & $0.011(0.008-0.016)$ & $2.920(0.284-7.331)$ & $2.43( \pm 0.172)$ & 3.795 & $Y=1.62+2.43 x$ \\
\hline 3 & 72 & $0.007(0.006-0.010)$ & $1.699(0.223-4.719)$ & $2.37( \pm .161)$ & 5.471 & $Y=2.4+2.37 x$ \\
\hline \multicolumn{7}{|c|}{ MACHILIPATNAM POPULATION } \\
\hline 1 & 24 & $0.244(0.018-0.468)$ & $6.519(0.365-8.063)$ & $3.32( \pm 0.291)$ & 3.15 & $Y=2.00+3.32 x$ \\
\hline 2 & 48 & $0.181(0.007-0.210)$ & $4.558(0.121-6.844)$ & $3.10( \pm 0.228)$ & 4.47 & $Y=2.50+3.10 x$ \\
\hline 3 & 72 & $0.0854(0.067-0.153)$ & $2.120(0.343-4.188)$ & $3.00( \pm 0.214)$ & 5.05 & $Y=3.80+3.00 x$ \\
\hline \multicolumn{7}{|c|}{ SUSCEPTIBLE RAJAHMUNDRY POPULATION } \\
\hline 1 & 24 & $0.008(0.006-0.015)$ & $0.978(0.328-3.647)$ & $2.57( \pm 0.175)$ & 10.007 & $Y=1.20+2.57 x$ \\
\hline 2 & 48 & $0.006(0.005-0.009)$ & $0.877(0.251-2.492)$ & $2.50( \pm 0.190)$ & 7.906 & $Y=2.00 .+2.50 x$ \\
\hline 3 & 72 & $0.004(0.003-0.005)$ & $0.659(0.128--1.247)$ & $2.41( \pm 0.225)$ & 12.451 & $Y=2.07+2.41 x$ \\
\hline
\end{tabular}

Lethal concentrations and 95\% fiducial limits (fl) were estimated using probit analysis (spss 16.0).

The chi-square test revealed the homogeneity of the test population $(\mathrm{p}<0.05 \%)$ 
Table.3 Degree of resistance acquired by the adults of Cryptolestes ferrugenius to malathion and deltamethrin

\begin{tabular}{|c|c|c|c|c|c|}
\hline \multirow[t]{2}{*}{ S. No. } & \multirow[t]{2}{*}{ Name of the strain } & \multirow[t]{2}{*}{$\mathbf{L C}_{50}$} & \multirow[t]{2}{*}{ LC $_{99.9}$} & \multicolumn{2}{|c|}{$\begin{array}{l}\text { Resistance Factor } \\
\text { In comparison with Rajahmundry population }\end{array}$} \\
\hline & & & & $\mathrm{LC}_{50}$ & LC 99.9 \\
\hline \multicolumn{6}{|c|}{ Malathion (50\% EC) } \\
\hline 1 & Machilipatnam & 0.104 & 4.90 & 34.66 & 4.14 \\
\hline 2 & Bapatla & 0.050 & 2.278 & 16.66 & 1.92 \\
\hline 3 & $\begin{array}{l}\text { Rajahmundry population } \\
\text { (Succeptible) }\end{array}$ & 0.003 & 1.184 & - & - \\
\hline \multicolumn{6}{|c|}{ Deltamethrin $(2.8 \%$ EC) } \\
\hline 1 & Machilipatnam & 0.0854 & 6.519 & 21.35 & 9.89 \\
\hline 2 & Bapatla & 0.007 & 1.699 & 1.75 & 2.57 \\
\hline 3 & $\begin{array}{l}\text { Rajahmundry population } \\
\text { (Succeptible) }\end{array}$ & 0.004 & 0.659 & - & - \\
\hline
\end{tabular}

Toxicity of Deltamethrin to different populations of C. ferrugineus

\section{Bapatla population}

The $\mathrm{LC}_{50}$ and $\mathrm{LC}_{99.9}$ values of deltamethrin at 24 HAT were 0.017 and 3.398 per cent, respectively for the Bapatla population of $C$. ferrugineus. Since there was a slight increase in the mortality of adults at 48 and $72 \mathrm{HAT}$, there was a decrease in the $\operatorname{LC}_{50}(0.011 \%$ and $0.007 \%)$ and at $\mathrm{LC}_{99.9}(2.920 \%$ and 1.699 $\%$ ), respectively (Table. 2). The slope (b) values of log concentration probit (lcp) lines were $2.29,2.43$ and 2.37 at 24,48 and 72 HAT, respectively. The chi-square test revealed the homogeneity of the test population $(\mathrm{P}<0.05 \%)$.

\section{Machilipatnam population}

The Machilipatnam population of $C$. ferrugineus has recorded the $\mathrm{LC}_{50}$ and $\mathrm{LC}_{99.9}$ values of 0.244 and 6.519 per cent, respectively for deltamethrin at 24 HAT (Table. 2). The corresponding $\mathrm{LC}_{50}$ and $\mathrm{LC}_{99.9}$ values at 48 and 72 HAT were $(0.181 \%$ and $4.558 \% ; 0.0854 \%$ and $2.120 \%$ ) due to slight increase in mortality. The slope (b) values of $\log$ concentration probit (lcp) lines were 3.22,
3.10 and 3.00 at 24,48 and 72 HAT, respectively.

\section{Susceptible Rajahmundry population}

The $\mathrm{LC}_{50}$ and $\mathrm{LC}_{99.9}$ values of deltamethrin for Rajahmundry population of $C$. ferrugineus at 24 HAT were 0.008 and 0.978 per cent respectively (Table. 2). Since there was a slight increase in the mortality of adults at 48 and $72 \mathrm{HAT}$, there was a decrease in the $\mathrm{LC}_{50}$ $(0.006 \%$ and $0.004 \%)$ and $\mathrm{LC}_{99.9}$ values $(0.877 \%$ and $0.659 \%)$. The slope (b) values of $\log$ concentration probit (lcp) lines of deltamethrin were 2.57 at $24 \mathrm{HAT}$ and 2.50 at 48 and 2.41 at 72 HAT, respectively. The chisquare test revealed the homogeneity of the test population $(\mathrm{P}<0.05 \%)$.

\section{Degree of resistance acquired by adults of C. ferrugineus to deltamethrin at 72 HAT}

Among three population of $C$. ferrugineus tested, Rajahmundry population has recorded lowest $\mathrm{LC}_{50}$ and $\mathrm{LC}_{99.9}$ values. The Machilipatnam population and Bapatla populations of $C$. ferrugineus showed 21.35 and 1.75 folds resistance at $\mathrm{LC}_{50}$ and 9.89 and 2.57 folds resistance at $\mathrm{LC}_{99.9}$ level to deltamethrin respectively in comparison with 
Rajahmundry population of $C$. ferrugineus, $\left(\mathrm{LC}_{50}=0.004 \%\right.$ and $\left.\mathrm{LC}_{99.9}=0.695 \%\right)$ at 72 HAT (Table. 3).

The $\mathrm{LC}_{50}$ and $\mathrm{LC}_{99.9}$ values of deltamethrin for Machilipatnam population in the present study at 72 HAT were 0.0854 and $2.120 \%$ which were higher when compared to the values $(0.0027$ and $0.1733 \%)$ reported by Madhumathi (1997). The increased levels of resistance to deltamethrin in the present investigation may be due to more usage of deltamethrin in the storage godowns after 1997. Moreover, the usage of deltamethrin in godowns is of recent one i.e; $1999-2000$ onwards.

The present results were similar to the findings of Kumar et al., (2010), who reported that a population of $T$. granarium has developed resistance which is ranged from 1.55 to 3.65 folds in six successive generations at 80 percent selection pressure. Similarly, Saxena and Sinha (1996) developed a deltamethrin resistant population of $T$. castaneum having more than 891 folds resistance through six generations of selection in the laboratory. The $\mathrm{LC}_{50}$ of the parent population was 0.00024 percent and that of sixth generation $\left(\mathrm{F}_{6}\right)$ was 0.2158 percent, respectively.

Bapatla populations showed 1.75 folds of resistance to deltamethrin and remaining Machilipatnam population has recorded 21.35 folds of resistance to deltamethrin when compared with the Rajahmundry population. Higher levels of resistance to deltamethrin in Machilipatnam population may be due to the heavy infestation of $C$. ferrugineus in Machilipatnam which has led to more usage of deltamethrin and continuous exposure might have led to occurrence of resistance to deltamethrin.

In conclusion the results showed the Bapatla and Machilipatnam populations of $C$. ferrugineus showed 16.66 and 34.66 folds resistance to malathion at $\mathrm{LC}_{50}$ level. Similarly, Bapatla and Machilipatnam populations of $C$. ferrugineus showed 1.75 and 21.35 folds resistance to deltamethrin at $\mathrm{LC}_{50}$ when compared to the susceptible Rajahmundry population. It can be concluded from this study that populations of $C$. ferrugineus have developed resistance against malathion and deltamethrin and these cannot be controlled by this insecticides. Higher doses or other pesticides are required to control resistant population. Secondly, development of resistance and the susceptibility in insects is a biochemical phenomenon which is evident from number of macromolecular derangements resistant and susceptible populations of $C$. ferrugineus. Future direction of the study to demonstrates the importance of research on insecticide resistance and the constant need to develop novel insecticides, and innovative strategies to prevent the development of insecticide resistance

\section{Acknowledgment}

The authors are thankful to Acharya N.G. Ranga Agricultural University for providing financial help during the course of study and also extend gratitude to ICAR- New Delhi for giving the opportunity to pursue this M.Sc. Agriculture in such a prestigious University by allotting a seat with fellowship through ICAR JRF examination.

\section{References}

Agricultural statistics at a glance, 2019-20. Ministry of Agriculture (Department of Agriculture and Cooperation, Directorate of Economics \& Statistics).

Aulakh, J., Regmi, A., Fulton, J. R and Alexander, C. E. 2013. Estimating post-harvest food losses: Developing a consistent global estimation framework. 
Badmin, J.S., 1990. IRAC survey of resistance of stored grain pests: Results and Progress. Proceedings of the Fifth International Working Conference on Stored Product Protection. Bordeaux, France. Pp. 973-982.

Champ, B.R., and Dyte, C.E. 1976. Report of the FAO global survey of pesticide susceptibility of stored-grain pests. FAO Plant Production and Protection Services No. 5. Food and Agricultural Organization of the United Nations, Rome.

Finney, D.J., 1971. Probit analysis. Cambridge University Press, London. Pp. 109.

Hill, D.S., 1992. Pests of stored products and their control. C B S Publshers and distributors 485, Jain Bhawan, Bhola Nath Nagar, Shandara, New Delhi. Pp. 274.

Kumar, M.K., C.Srivastava and Garg, A.K. 2010. In vitro selection of deltamethrin resistant strain of Trogoderma granarium and its susceptibility to insecticides. Annals of Plant Protection Sciences. 18 (1): 26-30.

Madhumathi, T. 1997. Assessment of insecticide resistance in Cryptolestes ferrugineus (Stephens) and its management. Ph. D Thesis, ANGRAU, Hyderabad, India.

Madhumathi, T., Subbaratnam, G.V., Murthy, M.L.N and Jayaraj, S. 2000. Insecticide resistance in Cryptolestes ferrugineus (Stephens) (Coleoptera: Cucujidae) in Andhra Pradesh. Pest Management and Economic Zoology. 8 (1): 5-10.

Pingale, S.V., 1976. Insects and mites attacking food grain. In Handling and Storage of Food Grains. Indian Council of Agricultural Research, New Delhi. Pp. 186.

Raffa, KF., and Priester, T.M. 1985. Synergists as research tools and control agents in agriculture. Journal of Agricultural Entomology. 2: 27-140.

Rossiter, L.C., Gunning, R.V and Rose, H.A. 2001. The use of Polyacrylamide Gel Electrophoresis for the investigation and detection of fenitrothion and chlorpyrifosmethyl resistance in Oryzaephilus surinamensis (L.) (Coleoptera, Silvanidae). Pesticide Biochemistry and Physiology. 69: 27-34.

Saxena, J.D., and Sinha, S.R. 1996. Decline of resistance in a laboratory selected deltamethrin resistant strain of Tribolium castaneum, after cessation of insecticidal selection pressure. Indian Journal of Entomology. 58 (4): 280-283.

Srinivasa,V., Reddy, K.D and Sridhar, Y. 2003. Management of sitophilus zeamais in stored maize using grain protectants. Indian journal of entomology. 65 (4): 492-495.

White, N.D.G., and Bell, R.J. 1995. Relative fitness of a malathion-resistant strain of Cryptolestes ferrugineus (Coleoptera: Cucujidae) when development and oviposition occur in malathion-treated and untreated wheat kernels. Journal of Stored Products. 26: 23-37.

White, N.D.G., and Watters, F.L. 1983. Incidence of malathion resistant strain in Tribolium castaneum and Cryptolestes ferrugineus populations collected in Canada. Processing of Third International Conference on Stored Product Entomology, Kansas State University, Manhattan, Kansas, USA. Pp. 290 -302.

\section{How to cite this article:}

Debjyoti Chakraborty and Madhumathi, T. 2020. Present scenario of insecticide resistance in Rusty Grain Beetle, Cryptolestes ferrugenius (Stephens) to Malathion and Deltamethrin in Andhra Pradesh, India. Int.J.Curr.Microbiol.App.Sci. 9(06): 4180-4188.

doi: https://doi.org/10.20546/ijcmas.2020.906.489 